\title{
Priority Sector Lending by Public and Private Sector Banks in India
}

\author{
D. Veena, G. V. Bhavani Prasad
}

Abstract: Priority Lending is critical to the inclusive growth in India. The credit distribution to the priority sectors is vital in ensuring that the economic growth is even and percolates down to all levels in the economy. RBI made it mandatory to the Scheduled Commercial Banks (SCB) in India for providing credit delivery to critical sectors identified as part of priority sector. RBI mandated all the banks should achieve the targets and sub targets of priority sector lending as minimum percent of Adjusted Net Bank Credit (ANBC) or Off - Balance sheet Exposure (OBE) whichever is higher. This paper aims at understanding the credit delivery to Priority Sector by Public Sector Banks (PSBs), Private Sector Banks (PrSBs), analyze the ability of the banks to meet the targets and sub targets as Agriculture Advances, Micro, Small and Medium Enterprises Advances and Weaker Sections Advances and whether these banks are meeting the recommendations of the $R B I$ in providing credit to different sub segments of priority sector especially, Agriculture, MSMEs and Weaker sections. Ratios were calculated to check the proportion of these priority advances in the total advances, the percentage of priority in the ANBC. The statistical tools are used to check the significant variation of priority lending by these banks. Public Sector banks are proved that they are dominant partners in this strategy for sustainability of financial inclusion through lending to all the target and sub targets as per the RBI norms. Major portion of PrSBs lending is towards MSMEs while PSB were targeting more on agriculture and weaker sections.

Keywords : Priority Sector, Public Sector Bank, Private Sector Bank, Adjusted Net Bank Credit, Off Balance Sheet Exposure, Total Advances, Agriculture, Micro, Small and Medium Enterprises and Weaker Sections.

\section{INTRODUCTION}

$\mathrm{P}$ riority Sector Lending' came through the idea of 'Direct Lending' by the banks to few needy and in adequately serviced sectors. RBI the central bank of India and also the Indian banks believed lending to the specific sectors and regulating the core sectors can bring about balanced growth, stability in the economy. Priority Sector includes the sectors of national importance, once they were not considered or neglected by the banks for the purpose of accessibility of credit are now considered to be as priority to provide credit as they are the corner stones for the country's true development.

Revised Manuscript Received on June 13, 2020.

* Correspondence Author

Fi Dr. D. Veena*, ICSSR PDF Scholar, University College of Commerce and Business Management, Kakatiya University, Warangal, Telangana State, India. Email: veenakoduri10@gmail.com.

Prof. G. V. Bhavani Prasad, Emeritus Professor, University College of Commerce and Business Management, Kakatiy University, Warangal, Telangana State, India. bhavaniprasadgv@gmail.com.

(C) The Authors. Published by Blue Eyes Intelligence Engineering and Sciences Publication (BEIESP). This is an open access article under the CC BY-NC-ND license (http://creativecommons.org/licenses/by-nc-nd/4.0/)
At Present the scope of the priority sector is very wide with many categories, targets and sub targets.

\section{PRIORITY SECTOR LENDING IN INDIA}

\section{A. History of Priority Sector Lending in India}

The following table presents the chronological history of priority sector lending in India which was published in Indian Economic Services Priority Sector Lending. The concept of priority sector lending has its roots in the constitution of India which emphasizes on inclusive growth.

\begin{tabular}{|l|lr|}
\hline $\begin{array}{l}\text { All India Rural } \\
\text { Credit } \\
\text { Committee, } \\
1966 .\end{array}$ & $\begin{array}{l}\text { Review } \\
\text { July, }\end{array}$ & $\begin{array}{l}\text { Recommendations for improving } \\
\text { complementary role along with } \\
\text { cooperative banks and institutions. }\end{array}$ \\
\hline $\begin{array}{l}\text { Social Control } \\
\text { Measure Over Banks, } \\
1967 .\end{array}$ & $\begin{array}{l}\text { The principle of Socialism is the base } \\
\text { for this concept, according to this each } \\
\text { and every bank is to align their operations } \\
\text { in line to meet the national objective. }\end{array}$ \\
\hline
\end{tabular}

National Credit Recommended to estimate the demand

Council, 1968. for the bank credit from different sectors, with the cooperation between co-operative banks and commercial banks to achieve the optimum utilization of resources and also helps to keep safe from the exploitative money lenders.

\begin{tabular}{l|l}
$\begin{array}{c}\text { Banking Laws } \\
\text { Amendment Act, } \\
\text { passed in 1968 came } \\
\text { in to force 1969 }\end{array}$ & $\begin{array}{l}\text { This act enables the government to } \\
\text { control and supervise all the affairs of } \\
\text { banks to keep consideration of national } \\
\text { objectives. }\end{array}$ \\
$\begin{array}{c}\text { Nationalization of } \\
\text { Banks, 1969. }\end{array}$ & $\begin{array}{l}\text { Fourteen major banks were } \\
\text { nationalized to make sure the credit to } \\
\text { neglected sectors instead of } \\
\text { concentrating more on economic power. }\end{array}$
\end{tabular}

Informal Study Priority sectors were formalized
Group on Statistics, according the committee $1972 . \quad$ recommendations.

Advises of RBI, Considering the recommendations of 1974. the committee RBI stated that banks should raise the share of the specified targeted sectors to 33.3 percent by March 1979 and private sector banks to reach a level of not less than one third of their total outstanding at par by March,1980.

Working Group on the Modalities of PSL chaired by Dr. K.S. Krishnaswamy, 1980.

Advised all commercial banks to achieve the target of PSL at 40 percent of the bank advances by 1985 and also specified sub targets of priority sector lending. 


\section{B. Categories of Priority Sector}

The Government of India and RBI defined the sectors eligible to be considered as part of priority sector (Indian Economic Service, Priority Sector Lending). In 1972,

-Agriculture

-Small Scale Industries

-Industrial Estates

-Road and Water transport operators

- Retail Traders

-Professional and self-employed persons

-Education

As per the RBI Circular dated July 7, 2016, eight categories have been identified under the head of priority sector lending which are

1. Agriculture (which includes the sub-categories namely Farm credit, Agriculture Infrastructure and Ancillary activities).

2. Micro, Small and Medium Enterprises

3. Export Credit

4. Education

5. Housing

6. Social Infrastructure

7. Renewable Energy

8. Others ware/ tool.

\section{Targets and Sub targets of Priority sector}

As part of its strategy to encourage the priority sector lending RBI specified targets and sub targets to SCBs in India.

The Targets and Sub-targets under PSL for all SCBs operating in India are mentioned in RBI Master Direction Priority Sector Lending Targets and Classification, RBI/FIDD/2016-17/33, are below:

Domestic scheduled commercial banks and foreign banks with 20 branches and above:

Total Priority Sector: 40 per cent of ANBC or Credit equivalent amount of Off-balance sheet exposure, whichever is higher.

Agriculture: 18 per cent of ANBC or Credit Equivalent Amount of Off-Balance Sheet Exposure, whichever is higher. Within the 18 per cent target for agriculture, a target of 8 percent of ANBC or Credit Equivalent Amount of Off-Balance Sheet Exposure, whichever is higher is prescribed for Small and Marginal Farmers.

Micro, Small and Medium Enterprises: 7.5 per cent of ANBC or Credit Equivalent Amount of Off-Balance Sheet Exposure, whichever is higher.

Advances to Weaker Sections: 10 percent of ANBC or Credit Equivalent Amount of Off-Balance Sheet Exposure, whichever is higher.

Additionally, domestic banks are directed to ensure that the overall lending to non-corporate farmers does not fall below the system-wide average of the last three years achievement. All efforts should be maintained to reach the level of 13.5 percent direct lending to the beneficiaries who earlier constituted the direct agriculture sector. The applicable system wide average figure as applicable to domestic banks and made applicable for foreign banks with 20 branches and above from FY 2019-20, for computing achievement under priority sector lending will be notified every year. For FY 2019-20, the applicable system wide average figure is 12.11 percent.

Foreign banks with less than 20 branches:

Total Priority Sector: 40 per cent of ANBC or Credit equivalent amount of Off-balance sheet exposure, whichever is higher, to be achieved in a phased manner by 2020 as under:

- 32 per cent in 2015-16

- 34 per cent in 2016-17

- 36 per cent in 2017-18

- 38 per cent in 2018-19 and

- 40 per cent in 2019-20.

The additional priority sector lending target of 2 percent of ANBC each year from 2016-17 to 2019-20 must be achieved by lending to sectors other than exports.

\section{ANBC and OBE}

ANBC and OBE are calculated as mentioned Master Direction FIDD. CO. Plan. BC No.08/04.09.01/2019-20.

Adjusted Net Bank Credit (ANBC): As per the Master Direction- Reserve Bank of India Priority Sector Lending -Targets and Classification) Directions, 2016, ANBC can be calculated by calculating the Net Bank Credit (NBC), and this NBC can be calculated by subtracting the Bills Rediscounted with RBI and other approved Financial institutions from Bank Credit in India, to this NBC Investments in Non-SLR categories under HTM category and other investments eligible to be treated as priority sector are added to get ANBC. Off Balance Sheet Exposure (OBE): The credit equivalent amount of a market related off-balance sheet transaction calculated using the current exposure method is the sum of the current credit exposure and potential future credit exposure to these contracts.

\section{REVIEW OF LITERATURE}

This R. K. Uppal (2009). [1]. studied the issues, trends and strategies of Indian priority sector advances and concluded that the public sector banks were not able to achieve the sub targets of priority advances because of high NPAs, low profits and transaction cost etc.

Ahmed (2010). [2]. found that the level of NPAs in priority sector advances of commercial banks and the recovery performance of priority sector advances of banks over the years by the statistical tools like correlation analysis, regression analysis, growth rate analysis, parametric tests. He concluded that the banks are not able to reach the prescribed target of lending to priority sector.

Dr Kewal Kumar, Atul Gambhir. (2012). [3]. concluded public sector banks have showed better private sector banks in priority lending but public sector banks needs to take care of bad debts and NPAs.

C.Bhujanga Rao, (2014). [4]. conducted a survey on appraisal of priority sector lending by commercial banks in India and the study revealed that the priority sector advances creating heavy NPAs.

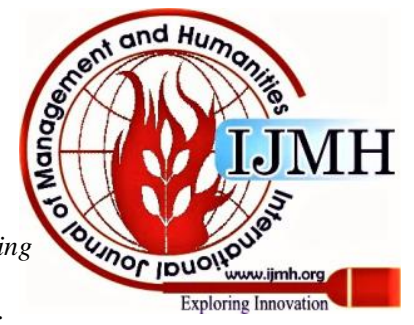


H.N. Harakantra et al. (2014). [5]. identified that lending to priority sector by private sector showed a growth rate 34 to 46 percent and public sector banks showed 38 to 42 percent and said private sector banks are better than public sector banks in priority lending.

Bhargav Pandya (2015). [6]. analyzed that priority sector advances showing high impact on the profitability of scheduled commercial banks in India by studying the variables Return on Assets, Return on Investment, Return on Equity, Ratio of Operating Profit and Ratio of Interest Income to Total Assets.

Shilpa Rani, Diksha Garg (2015). [7]. identified in their study that the public and private sector banks not able to meet the RBI mentioned targets, the banks are neglecting the agriculture advances, small scale industries.

Dr. Ashish C. Makwana (2015). [8]. concluded that credit management of selected banks are very poor like sanctioning the credit to priority sector even the public sector banks have less concern towards the development of priority sector.

Dave (2016). [9]. Analyzed priority sector lending for selected public sector banks of India selected bank like SBI, PNB, CANARA bank, BOB and BOI. Statistical analysis showed all the selected banks are following norms lending towards priority sector advances nearer to on third or one fourth of total advances of the banks.

Kurbanhusain A. Kadiwala (2017). [10]. examined the priority sector lending by Indian commercial bank, he found that there is significant difference in priority sector lending between selected banks of BOB and BOI are performing good as compare to other selected banks.

Dr. O. Hari babu et al. (2018). [11] identified Indian commercial banks are not successful in achieving the norms of RBI only advances to small scale industries are satisfying norms. Lending to weaker sections is below the norms due to over dues and non-performing assets.

Need for the Study: Based on the previous studies and RBI directives from time to time, Agriculture, MSMEs and Weaker Sections seem to be the primary focus of Priority sector lending. However, very few studies seem to be found on the distinction between the Public sector and private sector banks in the priority sector credit, the extent to which they adhered to RBI directives with reference to targets and sub targets.

\section{OBJECTIVES OF THE STUDY AND RESEARCH METHODOLOGY}

\section{A. Objectives of the Study:}

1. To have an overview of priority sector lending in India.

2. To study whether the SCBs are able to meet the norms prescribed by RBI.

3. To analyze the proportion of priority sector advances to ANBC by Public Sector Banks and Privates Sector Banks.

4. To examine the proportion of priority sector advances to Total advances by Public Sector Banks and Privates Sector Banks.

5. To examine whether there is significant difference between public and private sectors banks in providing credit to priority sector.

B. Research Methodology: This paper studies the Priority Sector Lending by Public Sector Banks, Private Sector Banks and targets and sub targets like Agriculture Advances, Micro, Small and Medium Enterprises Advances and Weaker Sections Advances. The data was collected from RBI Annual Reports, RBI Bulletins, A Report on Trend and Progress of Banking in India, Handbook of Statistics of Indian Economy. The study attempts to analyze the proportion of priority sector advances and its target sectors to Adjusted Net Bank Credit (ANBC) and total advances for Public Sector Banks (20), Private Sector Banks (22) for the period of 2010-19. The comparisons between PSBs and PrSBs in their ability to meet RBI prescribed norms for target sector is also analyzedsector banks in the priority sector credit, the extent to which they adhered to RBI directives with reference to targets and sub targets.

\section{DATA ANALYSIS}

The ratios of PSA to ANBC and Total Advances, the sub categories of PSL ratios were calculated to see the trend of the PSL and it is compared with the RBI norms to know whether banks are meeting the prescribed norms of priority or not. $\mathrm{T}$ statistic is used to identify the significant differences between PSBs and PrSBs in priority sector lending.

\section{A. Analysis of Ratio of Priority Sector Advances to ANBC of PSBs, PrSBs:}

The aggregate advances to priority sector advances (as a proportion to ANBC) by PSBs and PrSBs provide with an idea regarding the extent of their commitment to the Sector.

Table 1: Ratio of Priority Sector Advances to ANBC of PSBs, PrSBS.

\begin{tabular}{|l|l|l|}
\hline Year & PSBs & PrSBs \\
\hline 2010 & 41.6 & 45.8 \\
\hline 2011 & 41.3 & $\mathbf{4 6 . 6}$ \\
\hline 2012 & 37.2 & 39.4 \\
\hline 2013 & $\mathbf{3 6 . 3}$ & $\mathbf{3 7 . 5}$ \\
\hline 2014 & 39.4 & 43.9 \\
\hline 2015 & 37.3 & 42.8 \\
\hline 2016 & 39.3 & 44.1 \\
\hline 2017 & 39.5 & 42.5 \\
\hline 2018 & 39.9 & 40.8 \\
\hline 2019 & $\mathbf{4 2 . 5 5}$ & 42.49 \\
\hline Average & 39.44 & $\mathbf{4 2 . 5 9}$ \\
\hline SD & 1.94 & 2.64 \\
\hline
\end{tabular}

Table 1, shows the ratio of PSA to ANBC of SCB for the period of 2010-19. All sector banks are meeting the norms of total priority that is 40 per cent of ANBC or OBC whichever is higher. The ratio of PSBs was more in 2010-11 again in 2019. Only in 2013 it is very low but from 2014-18 the ratio is around 39 finally in 2019 it become 42.55 with an average 39.44 and SD 1.94 which is a good sign.

PrSBs ratio was 45.8 in 2010 showed its highest 46.6 in 2011 and reached to least 37.5 in 2013 and finally reached to 42.49 in 2019 with an average of 42.59 and SD of 2.64. Only in two years in 2012,2013 the ratio is less than 40 per cent in the remaining years it is more than the prescribed per cent.

Published By:

Blue Eyes Intelligence Engineering

\& Sciences Publication

DOI:10.35940/ijmh.J0992.0641020

Journal Website: www.ijmh.org

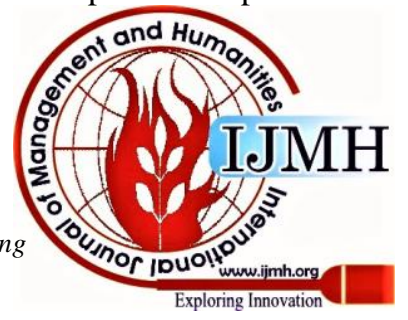


This tells us that the PrSBs are following the recommendations of priority by $\mathrm{RBI}$. PrSBs ratio is better than the remaining sector banks.

All the banks showed the least ratios in 2013 because of re-prioritizing the priority sector lending in India. PrSBs showed highest average of 42.59 with 2.64 Standard Deviation. Though PrSBs showed higher average lending, the highe Table 2: T Statistics for Ratio of Priority Sector Advances to ANBC between PSBs, PrSBs $r$ SD indicates higher volatility in the lending over the study period. PSBs have more consistent performance compared to PrSBs during the period of study.

Hypothesis Testing:

HO: There is no significant difference between PSBs, PrSBs in the Priority sector lending as proportion of ANBC.

H1: There is significant difference between PSBs, PrSBs in the Priority sector lending as proportion of ANBC.

The results of the tests have shown in the Table no.2.

\begin{tabular}{|c|c|c|}
\hline $\begin{array}{c}\text { Pearson } \\
\text { Correlation }\end{array}$ & T Stat & $\begin{array}{c}\text { T } \\
\text { Value }\end{array}$ \\
\hline 0.69 & 4.99 & 2.26 \\
\hline \multicolumn{3}{|c|}{ Tst $<$ Tcv } \\
\hline & $\mathrm{H}_{1}$ is accepted \\
\hline
\end{tabular}

According to the $\mathrm{T}$ Statistic results, there is significant difference between PSBs, PrSBs in the Priority sector lending as proportion of ANBC.

B. Analysis of Ratio of Priority Sector Advances to Total Advances by SCBs: The advances to priority sector as proportion of total advances is another measure indicating SCBs commitment to the sector.

Table 3: Ratio of Priority Sector Advances to Total Advances of PSBs, PrSBs.

\begin{tabular}{|l|l|l|}
\hline Year & PSBs & PrSBs \\
\hline 2010 & 46.87 & 33.94 \\
\hline 2011 & 44.52 & 31.24 \\
\hline 2012 & 41.49 & 29.64 \\
\hline 2013 & 41.49 & 28.64 \\
\hline 2014 & 45.78 & 34.59 \\
\hline 2015 & 40.68 & 32.92 \\
\hline 2016 & 35.49 & 33.41 \\
\hline 2017 & 35.79 & 32.03 \\
\hline 2018 & 36.37 & 30.22 \\
\hline 2019 & 38.91 & 30.63 \\
\hline Average & 40.74 & 31.73 \\
\hline SD & 3.91 & 1.87 \\
\hline (Source: A Report on Trend and Progress of Banking in India)
\end{tabular}

Table 3 shows the ratio of PSA to Total Advances of SCBs for the period 2010-19. PSBs showed the highest ratio 46.87 among all the banks in 2010 than it reached tis least 35.49 in 2016 and finally reached to 38.49 with an average of 40.74 , SD of 3.91. Whereas PrSBs ratio was 33.94 in 2010, reached to its lowest 28.64 in 2013 and finally it stood at 30.63 in 2019 with an average of 31.73 and SD of 1.87. PSBs showed high average 40.74, SD 3.91 and the least ratio with PrSBs. PSBs maintained higher average as a proportion of total advances while PrSBs have lower average. PSBs indicated better performance for priority sector lending when the proportion to total advances is considered.

Hypothesis Testing:
HO: There is no significant difference between PSBs, PrSBs in the Priority sector lending as proportion of Total Advances.

H1: There is significant difference between PSBs, PrSBs in the Priority sector lending as proportion of Total Advances. The results of the tests have shown in the Table no.4.

\section{Table 4: T Statistics for Ratio of Priority Sector Advances} to Total Advances between PSBs, PrSBs

\begin{tabular}{|l|l|l|}
\hline $\begin{array}{c}\text { Pearson } \\
\text { Correlation }\end{array}$ & T Stat & $\begin{array}{c}\text { T Critical } \\
\text { Value }\end{array}$ \\
\hline 0.27 & 7.05 & 2.26 \\
\hline \multicolumn{3}{|c|}{ Tst $>$ Tcv } \\
\hline \multicolumn{3}{|c|}{ H1 is accepted }
\end{tabular}

According to the $\mathrm{T}$ Statistic results, there is significant difference between PSBs, PrSBs in the Priority sector lending as proportion of Total Advances.

\section{Analysis of Ratio of Agriculture Advances to ANBC of PSBs, PrSBs:}

The aggregate advances to Agriculture sector as a proportion to ANBC by PSBs and PrSBs provide with an idea regarding the extent of their commitment to the Sector.

Table 5: Ratio of Agriculture Advances to ANBC of PSBs, PrSBs.

\begin{tabular}{|l|l|l|}
\hline Year & PSBs & PrSBs \\
\hline 2010 & 17.9 & 19.4 \\
\hline 2011 & 16.5 & 15.7 \\
\hline 2012 & 15.8 & 14.3 \\
\hline 2013 & 15 & 12.8 \\
\hline 2014 & 17 & 13.9 \\
\hline 2015 & 16.5 & 14.8 \\
\hline 2016 & $\mathbf{1 8 . 4}$ & $\mathbf{1 8 . 6}$ \\
\hline 2017 & 18.3 & 16.5 \\
\hline 2018 & 18 & 16.2 \\
\hline 2019 & 18.12 & 16.31 \\
\hline Average & $\mathbf{1 7 . 1 5}$ & 15.85 \\
\hline SD & 1.11 & 1.94 \\
\hline
\end{tabular}

Table 5 shows the ratio of agriculture advances to ANBC by SCBs for the period of 2010-19. The ratio which is prescribed by RBI is 18 per cent. The ratio was 17.9 in 2010, the ratio was decreasing for the period 2011-13 and the least was 15 in 2013 and the highest ratio was 18.4 in 2016 finally the ratio stood at 18.12 in 2019 with an average 17.15, SD of 1.11 . the PSBs average is less than the prescribed ratio.

PrSBs ratio was 19.4 in 2010, it started decreasing from 2011-15 and the least ratio was 12.8 in 2013, the highest was 18.6 in 2016 and finally stood at 16.31 in 2019 with an average 15.85, SD of 1.94. PrSBs ratio is less than the prescribed ratio. The performance of both the sector banks is very close. However, PSBs were doing better job of lending to Agriculture. Blue Eyes Intelligence Engineering \& Sciences Publication

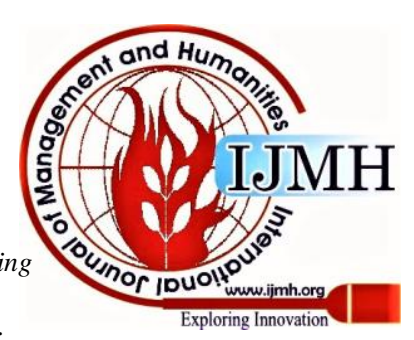


Hypothesis Testing:

HO: There is no significant difference between PSBs, PrSBs in the Agriculture sector lending as proportion of ANBC.

H1: There is significant difference between PSBs, PrSBs in the Agriculture sector lending as proportion of ANBC.

The results of the tests have shown in the Table no.6.

Table 6: T Statistics for Ratio of Agriculture Advances to ANBC of PSBs, PrSBs.

\begin{tabular}{|l|l|l|}
\hline $\begin{array}{l}\text { Pearson } \\
\text { Correlation }\end{array}$ & $\begin{array}{l}\text { T Stat } \\
\left(\mathrm{T}_{\mathrm{ST}}\right)\end{array}$ & $\begin{array}{l}\text { T Critical } \\
\text { Value }\left(\mathrm{T}_{\mathrm{CV}}\right)\end{array}$ \\
\hline 0.80 & 3.15 & 2.26 \\
\hline \multicolumn{3}{|c|}{$\mathbf{T}_{\mathrm{ST}}>\mathbf{T}_{\mathbf{C V}}$} \\
\hline \multicolumn{3}{|c|}{$\mathbf{H}_{\mathbf{1}}$ is Accepted } \\
\hline
\end{tabular}

According to the $\mathrm{T}$ Statistic results, there is significant difference between PSBs, PrSBs in the Agriculture sector lending as proportion of ANBC.

\section{Analysis of Ratio of Agriculture Advances to Total} Advances of PSBs, PrSBs:

The aggregate advances to Agriculture sector as a proportion to Total Advances by PSBs and PrSBs provide with an idea regarding the extent of their commitment to the Sector.

\begin{tabular}{|l|l|l|}
\hline Year & PSBs & PrSBs \\
\hline $\mathbf{2 0 1 0}$ & $\mathbf{2 0 . 2 1}$ & $\mathbf{1 4 . 3 4}$ \\
\hline $\mathbf{2 0 1 1}$ & 17.96 & 11.55 \\
\hline $\mathbf{2 0 1 2}$ & 17.57 & 10.78 \\
\hline $\mathbf{2 0 1 3}$ & 17.15 & $\mathbf{9 . 7 9}$ \\
\hline $\mathbf{2 0 1 4}$ & 19.43 & 11.01 \\
\hline $\mathbf{2 0 1 5}$ & 17.57 & 11.28 \\
\hline $\mathbf{2 0 1 6}$ & 16.17 & 13.76 \\
\hline $\mathbf{2 0 1 7}$ & 16.61 & 12.44 \\
\hline $\mathbf{2 0 1 8}$ & 16.36 & 11.95 \\
\hline $\mathbf{2 0 1 9}$ & 16.57 & 11.75 \\
\hline Average & $\mathbf{1 7 . 5 6}$ & 11.86 \\
\hline SD & 1.27 & 1.29 \\
\hline
\end{tabular}

Table 7shows the ratio of agriculture advances to total advances by SCBs for the period of 2010-19. PSBs ratio was 20.21 in 2010 after that it started decreasing and reached to its least 16.17 in 2016. Finally, it is 16.57 in 2019 with an average of 17.56 , SD of 1.27 . PrSBs were 14.34 which are the highest in 2010 and the least 9.79 in 2013 by the year ending 2019 it is 11.75 with an average 11.86, SD of 1.29. PSBs showed highest average of 17.56 with least SD1.27. The PSBs are better performing while funding agriculture. However, PSBs were doing better job of lending to Agriculture.

Hypothesis Testing:

HO: There is no significant difference between PSBs, PrSBs in the MSME sector lending as proportion of ANBC.

H1: There is significant difference between PSBs, PrSBs in the MSME sector lending as proportion of ANBC.

The results of the tests have shown in the Table no.8.
Table 8: T Statistics for Ratio of Agriculture Advances to Total Advances by PSBs, PrSBs.

\begin{tabular}{|c|c|c|}
\hline $\begin{array}{c}\text { Pearson } \\
\text { Correlation }\end{array}$ & T Stat & $\begin{array}{c}\text { T Critical } \\
\text { Value }\end{array}$ \\
\hline 0.15 & 10.24 & 2.262157 \\
\hline \multicolumn{3}{|c|}{ Tst $>$ Tcv } \\
\hline H1 is Accepted
\end{tabular}

According to the T Statistic results, there is significant difference between PSBs, PrSBs in the MSME sector lending as proportion of ANBC.

\section{E. Analysis of Ratio of Micro, Small and Medium Enterprises Advances to ANBC of PSBs, PrSBs:}

The aggregate advances to Micro, Small and Medium Enterprises advances as a proportion of ANBC by PSBs and PrSBs provide with an idea regarding the extent of their commitment to the Sector.

Table 9: Ratio of Micro, Small and Medium

Enterprises Advances to ANBC of PSBs, PrSBs.

\begin{tabular}{|c|l|l|}
\hline Year & PSBs & PrSBs \\
\hline 2010 & 13.3 & 13.8 \\
\hline 2011 & $\mathbf{1 5 . 1}$ & 16.4 \\
\hline 2012 & 13.1 & 15.2 \\
\hline 2013 & 13.5 & 16.2 \\
\hline 2014 & 14.5 & 17.6 \\
\hline 2015 & 14.2 & 17.6 \\
\hline 2016 & 14.9 & 20.4 \\
\hline 2017 & $\mathbf{6 . 3}$ & 8.3 \\
\hline 2018 & 6.4 & $\mathbf{7 . 9}$ \\
\hline 2019 & 7.32 & 7.92 \\
\hline Average & 11.86 & 14.1 \\
\hline Standard & 3.46 & $\mathbf{4 . 3 1}$ \\
\hline Deviation & & \\
\hline
\end{tabular}

(Source: Report on Trend and Progress of Banking in Indi, RBI repots.)

Table 9 shows the ratio of Micro, Small and Medium Enterprises advances to ANBC by SCBs for the period of 2010-19.

The RBi prescribed ratio is 7.5 per cent of ANBC or OBC whichever is higher. PSBs ratio was 13.3 in 2010, showed its highest 15.1 in 2011 from 2010 to 2016 it is more than 7.5 per cent and reached its least 6.3 in 2017, finally it is 7.32 in 2019 with an average of 11.86, SD of 3.46.

PrSBs ratio was 13.8 in 2010 and reached its highest 20.4 in 2016, finally it decreased to 7.92 in 2019 with an average of 14.13, SD of 4.31. In all the years the ratios were more than the RBI prescribed ratio. PrSBs performed better while financing MSMEs.

Hypothesis Testing:

HO: There is no significant difference in the proportion of Micro, Small and Medium Enterprises Advances to ANBC between PSBs, PrSBs.

$\mathrm{H} 1$ : There is significant difference in the proportion of Micro, Small and Medium Enterprises Advances to ANBC between PSBs, PrSBs.

The results of the tests have shown in the Table no. 10 .

Table 10: T Statistics for Ratio of Micro, Small and Medium Enterprises Advances to ANBC between PSBs, PrSBs.

Published By:

Blue Eyes Intelligence Engineering

\& Sciences Publication

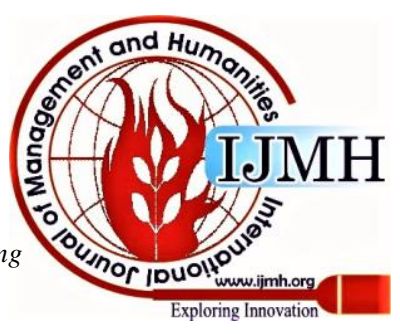




\begin{tabular}{|l|c|c|}
\hline $\begin{array}{c}\text { Pearson } \\
\text { Correlation }\end{array}$ & T Stat & $\begin{array}{c}\text { T } \text { Critical } \\
\text { Value }\end{array}$ \\
\hline 0.96 & -4.79 & 2.26 \\
\hline Tst $<$ Tcv \\
\hline H0 is fail to rejected \\
\hline
\end{tabular}

The aggregate advances to Micro, Small and Medium Enterprises advances as a proportion of Total Advances by PSBs and PrSBs provide with an idea regarding the extent of their commitment to the Sector.

Table 11: Ratio of Micro, Small and Medium Enterprises Advances to Total Advances of PSBs, PrSBs.

\begin{tabular}{|c|c|c|}
\hline Year & PSBs & PrSBs \\
\hline 2010 & 14.99 & 10.25 \\
\hline 2011 & 16.3 & 11.01 \\
\hline 2012 & 14.55 & 11.43 \\
\hline 2013 & 15.46 & 12.39 \\
\hline 2014 & 16.61 & 13.91 \\
\hline 2015 & 15.11 & 13.44 \\
\hline 2016 & 13.12 & 15.07 \\
\hline 2017 & 5.67 & 6.24 \\
\hline 2018 & 5.82 & 5.81 \\
\hline 2019 & 6.7 & 5.71 \\
\hline Average & 12.43 & 10.53 \\
\hline $\begin{array}{l}\text { Standard } \\
\text { Deviation }\end{array}$ & 4.27 & 3.3 \\
\hline
\end{tabular}

(Source: Report on Trend and Progress of Banking in India, RBI repots.)

Table 11shows the ratio of Micro, Small and Medium Enterprises advances to total advances by SCBs for the period 2010-19. PSBs ratio was 14.99 in 2010 the ratio reached its least 5.67 in 2017 and finally it is 6.7 in 2019 with average 12.43, SD of 4.27. PrSBs ratio was 10.25 in 2010 reached its highest 15.07 in 2016 and the ratio started decreasing and it recorded its least ratio 3.86 in 2019 with an average 7.99, SD of 3.07. PSBs are better than PrSBs but overall both the sectors are meeting the norms of RBI.

Hypothesis Testing:

HO: There is no significant difference in the proportion of Micro, Small and Medium Enterprises Advances to Total Advances between PSBs, PrSBs.

H1: There is significant difference in the Ratio of Micro, Small and Medium Enterprises Advances to Total Advances between PSBs, PrSBs.

The results of the tests have shown in the Table no. 12.

Table 12: T Statistics for Ratio of Micro, Small and Medium Enterprises Advances to Total Advances between PSBs, PrSBs.

\begin{tabular}{|c|c|c|}
\hline $\begin{array}{c}\text { Pearson } \\
\text { Correlation }\end{array}$ & T Stat & $\begin{array}{c}\text { T Critical } \\
\text { Value }\end{array}$ \\
\hline 0.86 & 2.6 & 2.26 \\
\hline \multicolumn{3}{|c|}{ Tst $>$ Tcv } \\
\hline \multicolumn{3}{|c|}{ H1 is accepted } \\
\hline
\end{tabular}

According to the $\mathrm{T}$ Statistic results, there is significant difference in the Ratio of Micro, Small and Medium Enterprises Advances to Total Advances between PSBs, PrSBs.

\section{F. Analysis of Ratio of Weaker Sections Advances to ANBC of PSBs, PrSBs:}

The aggregate advances to Weaker Sections as a proportion of ANBC by PSBs and PrSBs provide with an idea regarding the extent of their commitment to the Sector.
Table 13: Ratio of Weaker Sections Advances to ANBC of PSBs, PrSBs.

\begin{tabular}{|c|l|l|}
\hline Year & PSBs & PrSBs \\
\hline $\mathbf{2 0 1 0}$ & 10.2 & 5.4 \\
\hline $\mathbf{2 0 1 1}$ & 9.9 & 5.6 \\
\hline $\mathbf{2 0 1 2}$ & 9.5 & 5.4 \\
\hline $\mathbf{2 0 1 3}$ & 9.8 & 5.7 \\
\hline $\mathbf{2 0 1 4}$ & 10.56 & 6.7 \\
\hline $\mathbf{2 0 1 5}$ & 10.42 & 6 \\
\hline $\mathbf{2 0 1 6}$ & 11.4 & 9.5 \\
\hline $\mathbf{2 0 1 7}$ & 11.4 & 9 \\
\hline $\mathbf{2 0 1 8}$ & 11.5 & 9.5 \\
\hline $\mathbf{2 0 1 9}$ & $\mathbf{1 1 . 7 3}$ & $\mathbf{1 0 . 6 3}$ \\
\hline Average & $\mathbf{1 0 . 6 4}$ & 7.34 \\
\hline SD & 0.77 & 1.96 \\
\hline
\end{tabular}

Table 13 shows the ratio of weaker sections advances to ANBC by SCBs for the period 2010-19. RBI prescribed ratio for weaker section advances is 10 per cent of ANBC or OBC whichever is higher. PSBs ratio was 10.2 in 2010, the least ratio 9.5 was recorded in 2012 and the highest is 11.73 in 2019 with the average 10.64 , SD of 0.77 . The ratio is less than prescribed ratio for the period 2011-13, in the remaining years it is more than the 10 percent.

PrSBs showed a least ratio 5.4 in 2010 with a lot of variations finally it showed its highest 10.63 in 2019 with average 7.34 , SD of 1.96. PrSBs ratio in all the years were less than the 10 percent but at last in the year 2019 it reached to the 10.63 with this the average is very low. PSBs have done better in the funding of weaker sections while compared to PrSBs.

Hypothesis Testing:

$\mathrm{HO}$ : There is no significant difference in the proportion of Weaker Section Advances to ANBC between PSBs, PrSBs.

$\mathrm{H} 1$ : There is significant difference in the proportion of Weaker Section Advances to ANBC between PSBs, PrSBs.

The results of the tests have shown in the Table no. 14.

Table 14: T Statistics for Ratio of Weaker Sections Advances to ANBC between PSBs, PrSBs.

\begin{tabular}{|c|c|c|}
\hline $\begin{array}{c}\text { Pearson } \\
\text { Correlation }\end{array}$ & T Stat & $\begin{array}{c}\text { T Critical } \\
\text { Value }\end{array}$ \\
\hline 0.96 & 7.97 & 2.26 \\
\hline \multicolumn{3}{|c|}{ Tst $>$ TcV } \\
\hline \multicolumn{3}{|c|}{ H1 is accepted } \\
\hline
\end{tabular}

According to the $\mathrm{T}$ statistic result, there is significant difference in the proportion of Micro, Small and Medium Enterprises Advances to ANBC between PSBs, PrSBs.

\section{G. Analysis of Ratio of Weaker Sections Advances to Total Advances of PSBs, PrSBs:}

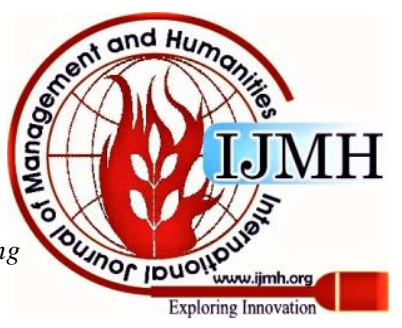


Table 15: Ratio of Weaker Sections Advances to Total Advances by SCBs.

\begin{tabular}{|l|l|l|}
\hline Year & PSBs & PrSBs \\
\hline 2010 & 11.47 & 4.03 \\
\hline 2011 & 10.66 & 3.26 \\
\hline 2012 & 10.6 & 4.03 \\
\hline 2013 & 11.23 & 4.42 \\
\hline 2014 & $\mathbf{1 2 . 2 4}$ & 4.48 \\
\hline 2015 & 11.36 & 4.57 \\
\hline 2016 & 9.98 & 7.02 \\
\hline 2017 & 10.35 & 6.79 \\
\hline 2018 & 10.44 & 7.04 \\
\hline 2019 & 10.72 & $\mathbf{7 . 6 6}$ \\
\hline Average & $\mathbf{1 0 . 9 1}$ & 5.33 \\
\hline SD & 0.63 & 1.52 \\
\hline \multicolumn{2}{|c|}{} \\
\hline
\end{tabular}

Table 15 shows the ratio of weaker sections advances to total advances by SCBs for the period of 2010-19. PSBs ratio was 11.47 in 2010, reached its highest 12.24 in 2014 and decreased to 9.98 in 2016 which is the least ratio by the year ending 2019 the ratio is 10.72 with average 10.91, SD 0.63 . PrSBs showed a ratio of 4.03 in 2010, the least ratio 3.266 was found in 2011with a lot of fluctuations finally it stood its highest 7.66 by the year ending 2019 with average 5.33, SD of 1.52. PSBs showed 10.91 highest averages and least 0.63 SD. Similarly, PSBs have performed better than PrSBs.

Hypothesis Testing:

HO: There is no significant difference in the proportion of Weaker Section Advances to Total Advances between PSBs, PrSBs.

H1: There is significant difference in the proportion of Weaker Section Advances to Total Advances between PSBs, PrSBs.

The results of the tests have shown in the Table no. 16 .

Table 16: T Statistics for Ratio of Weaker Sections Advances to ANBC between PSBs, PrSBs.

\begin{tabular}{|c|c|c|}
\hline $\begin{array}{c}\text { Pearson } \\
\text { Correlation }\end{array}$ & T Stat & $\begin{array}{c}\text { T Critical } \\
\text { Value }\end{array}$ \\
\hline-0.54 & 8.63 & 2.26 \\
\hline \multicolumn{3}{|c|}{ Tst $>$ Tcv } \\
\hline \multicolumn{3}{|c|}{ H1 is accepted } \\
\hline
\end{tabular}

According to $\mathrm{T}$ stat result, there is significant difference in the proportion of Weaker Section Advances to Total Advances between PSBs, PrSBs.

\section{FINDINGS}

- PSBs, PrSBs showed the least ratios in 2013 because of re-prioritizing the priority sector lending same period in India. PrSBs showed highest average of 42.59 with a standard deviation of 2.64 for the ratio of Priority sector lending to ANBC. The statistical test proved that there is no significant difference in the Ratio of Priority sector lending to ANBC between PSBs, PrSBs. However, the PSBs have shown relatively consistent performance as indicated by lower standard deviation.

- But coming to the ratio of priority sector lending to Total Advances between PSBs, PrSBs, the PSBs showed high average 40.74, SD 3.91 and the least ratio with PrSBs and the test proved that there is significant difference in the Ratio of priority sector lending to Total Advances between
PSBs, PrSBs. PSBs showed better performance in priority sector lending.

- The PSBs are providing more priority advances out of its total advances perhaps both the sectors are satisfying the norms RBI norms of 4 percent of ANBC.

- Coming to priority sector targets, Advances to Agriculture sector PrSBs ratio is less than the prescribed ratio of RBI 18 percent of ANBC. Statistically there is significant difference in the Ratio of Agriculture Advances to ANBC between PSBs, PrSBs. Here too the PSBs have shown better adherence and higher lending to Agriculture.

- PSBs showed highest average of 17.56 with least SD of 1.27 regarding Ratio of Agriculture Advances to Total Advances between PSBs, PrSBs. There is significant difference in the Ratio of Agriculture Advances to Total Advances between PSBs, PrSBs which is statistically proven. The PSBs have done better here too.

- Regarding Advances to Micro, Small and Medium Enterprises in all the years the ratios were higher than the RBI prescribed ratio that is 7.5 percent ANBC, for both the sector banks. There is no significant difference in the Ratio of Micro, Small and Medium Enterprises Advances to ANBC between PSBs, PrSBs. Surprisingly PrSBs average is 14.13 , SD 4.31 higher than the PSBs

- With reference to the Ratio of Micro, Small and Medium Enterprises Advances to Total Advances between PSBs and PrSBs, PSBs showed better average than PrSBs but overall both the sectors are meeting the norms of RBI it is statistically proved that there is significant difference in the Ratio of Micro, Small and Medium Enterprises Advances to Total Advances between PSBs, PrSBs. This explains PSBs are lending possible advances to Micro, Small and Medium Enterprises from its total advances.

- In the area of Advances to Weaker sections, PrSBs ratio in all the years were less than the 10 percent which is prescribed ratio by RBI but in the year 2019 it reached to the 10.63 but the average is very low and statistically proved that there is significant difference in the Ratio of Weaker Sections Advances to ANBC between PSBs, PrSBs. Private sector Banks were mostly behind the Public Sector Banks in funding Weaker Sections.

- In the case of the Ratio of Weaker Sections Advances to Total Advances between PSBs, PrSBs the PSBs showed 10.91 highest averages and least 0.63 SD relatively. There is significant difference in the Ratio of Weaker Sections Advances to Total Advances between PSBs, PrSBs.

\section{CONCLUSIONS}

Public Sector Banks are the main pillars for the successful lending to priority sectors in India, the active participation by PSBs in meeting the targets of priority lending can increase the economy of India and also these banks are the motivating factor for all the banks in order to reach the targets of priority as well as the national interest of lending. PSBs are actively meeting RBI norms including agriculture, Micro, Small and Medium Enterprises and weaker sections but coming to PrSBs, these banks are only concentrating to meet the RBI norms and unable to lend the equal proportion from total advances as PSBs.

\section{Published By:}

Blue Eyes Intelligence Engineering

\& Sciences Publication

DOI:10.35940/ijmh.J0992.0641020

Journal Website: www.ijmh.org

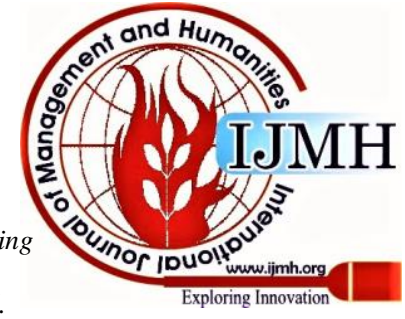


Compared to PSBs, PrSBs are lending more to Micro, Small and Medium Enterprises to gain better returns. They have shown a weakness to shy away from funding Agriculture and Weaker Section thus negating the very objective of priority lending i.e., inclusive growth. RBI needs to impress upon the PrSBs to meet their share of lending obligation if the final target of inclusive growth needs to be achieved.

\section{REFERENCES}

1. Uppal, RK. Priority Sector Advances: Trends, Issues and Strategies Journal of Accounting and Taxation, 1(5), 2005, pp.79-84.

2. Ahmed, J. U. D. Priority sector lending by commercial banks in India: A case of Barak Valley. Asian Journal of Finance \& Accounting, 2(1), 2010, 92.

3. Dr. Kewal Kumar et al. Commercial Banks Financing Priority Sector: An Impetus to Economy (A Study of Problems and Prospects). IOSR Journal of Business and Management, 1(5), 2012, pp. 45-48.

4. C.Bhujanga Rao, Appraisal of Priority Sector Lending by commercial banks in India, 27 feb

5. E58.

6. H.N. Harakantra et al. Priority Sector Lending of Commercial Banks in North Kanara District: An Overview. International Journal of Scientific Research, 3(3), 2014, pp. 68-69.

7. Pandya, D. B. Impact of Priority Sector Advances on Banking Profitability: Evidence from Scheduled Commercial Banks of India. BVIMSRs Journal of Management Reserach , 7 (2), 2015, pp. 75-81.

8. Rani, Diksha Garg. Priority Sector Lending: Trends, Issues and Strategies, International Journal of Management and Social Sciences Research (IJMSSR), 4(1), 2015. Pp. 24-28.

9. Dr. Ashish C. Makwana, An Analysis of Priority Sector Lending - As A Part of An Analysis of Priority Sector Lending - As A Part of Credit Management in Public Sector Banks \& Private Sector Banks, KCG Portal Genera.ls, Continuous issue- 15, 2015, pp.1-6.

10. Dave, D. K. A Study of Priority Sector Lending for Selected Public Sector Banks of India. IJRAR-International Journal of Research and Analytical Reviews, 3(3), 2016, pp. 84-86.

11. Kurbanhusain A. Kadiwala, A Study on Priority Sector Lending by Public Sector Banks and Private Sector Banks in India. International Journal of Research in All Subjects in Multi Languages, 5(2), 2017, pp. 67-71.

12. Dr. O. Hari babu, A. Srinivasulu, Dr.R.V.S.S. Nagabhushan Rao. Statistical Analysis of Priority Sector Credit by Commercial Banks in India. International Journal of Trend in Scientific Research and Development, 2(5), 2018, 253-260.

13. S.Manjusree, Dr. K.V. Giridhar, Problems and Prospects of Priority Sector Lending, Shanlax International Journal of Commerce, 6(2), 2018, pp.155-161.

14. RBI Annual Reports 2010-2019.

15. Hand book of Statistics of Indian Economy 2010-19.

16. A Report on Trend and Progress of Banking in India 2010-19.

17. http: www.dbie.rbi

\section{AUTHORS PROFILE}

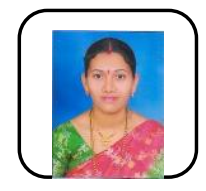

Dr. D. Veena, ICSSR, Post-Doctoral Fellow (PDF) Scholar, University College of Commerce and Business Management. Received Ph.D. in 2016, M.B.A. from Kakatiya University in 2005. Had 12 years of teaching experience and published 13 articles in national and international journals. Participated in national and international conferences and workshops. Joined ICSSR PDF scholar in 2018-19 and doing research on banking sector. Interested towards research and presented paper in World Finance \& Banking Symposium in 2014 Singapore, Second International Conference on Innovation Challenges in Multidisciplinary Research \& Practices in Kula Lumpur, Malaysia during 2014 and Participated and presented the research paper titled "Impact of RBIs Liquidity Policies on the Profitability of Commercial Banks" in Tokyo 40th International Conference on "Business, Economics, Social Science \& Humanities" (BESSH-2019) at Tokyo, Japan and many national level conferences.

Prof. G.V. Bhavani Prasad, Emeritus Professor (UGC), Kakatiya University, Warangal, has about 40 years of academic and research experience. He was Dean, Faculty of Commerce and Business Management, Kakatiya

Published By:

University, Warangal, India. He guided $25 \mathrm{Ph}$. D. thesis in the field of Commerce and Business Management. He published 51 research papers in national and international journals. He was chairperson of national and international seminars and conferences. He was awarded State Teacher Award in the year 2013. He was awarded CMC (Certified Management Consultant) by ICMCI, USA. Presently he is supervising research studies and consultancy projects.

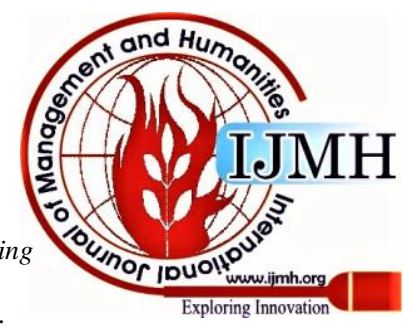

